\title{
Evaluation of the Effect of Topping on Cannabidiol (CBD) Content in Two Industrial Hemp (Cannabis sativa L.) Cultivars
}

\author{
Antigolena FOLINA ${ }^{1}$, Ioanna KAKABOUKI ${ }^{1}$, Evangelia TOURKOCHORITI ${ }^{1}$, Ioannis ROUSSIS ${ }^{1}$, Harry \\ PATEROULAKIS ${ }^{2}$, Dimitrios BILALIS ${ }^{1 *}$ \\ ${ }^{1}$ Agricultural University of Athens, Department of Crop Science, Laboratory of Agronomy, 75 Iera Odos \\ Str., 11855 Athens, Greece. \\ ${ }^{2}$ CBD Extraction PEF \\ *corresponding author: bilalisdimitrios@gmail.com
}

BulletinUASVM Horticulture 77(1) / 2020

Print ISSN 1843-5254, Electronic ISSN 1843-5394

DOI:10.15835/buasvmcn-hort: 2019.0021

\begin{abstract}
In order to define the finest cultivation practices for two of the most commercial hemp cultivars ('Fedora 23' and 'Futura 75') under the Mediterranean climate, the treatment of topping was applied in hemp crop in Central Greece. The object of the study was to assess if topping can increase the cannabidiol (CBD) production. In addition, the growth of the two cultivars was also investigated. Our results showed that the treatment of topping and cultivar affected the CBD content. The inflorescence compactness index and the number of nodes were affected by cultivar and topping. The number of inflorescences on secondary shoots was affected only by topping. The leaf area was affected by the interaction of cultivar and topping. The maximum height was recorded in un-topped Futura 75 plants, while the highest fresh and dry weight were found in topped Futura 75 plants. The total inflorescence dry matter was higher in topped plants.
\end{abstract}

Keywords: CBD, 'Fedora 23', ‘Futura 75', hemp, topping

\section{Introduction}

In recent years, the ancient cultivation of cannabis has been revived. Hemp began to be recultivated for fiber in the early part of this century. High fiber yield was one of the main reasons for replacing cotton because hemp is considered environmentally friendly compared to the two crops (Amaducci et al., 2012; Allegret et al., 2013; Jonaitiene et al., 2016). Today, besides the growth of medicinal or recreational cannabis, the hemp is also grown for oil extracted from the resins produced by the flowers. The cannabidiol (CBD) oil is now widely used in the food, pharmaceutical and cosmetic industries (Turner et al., 1980). Hemp is often touted as a super-crop with myriad uses. Essential oil obtained from hemp contains volatile compounds, mainly monoterpenes, sesquiterpenes, and other terpenoid-like compounds (Farooq et al., 2006).

Cannabis components are many, while from the cannabinoids, the well-known for their healing properties are cannabidiol (CBD) and tetrahydrocannabinol $\left(\Delta^{9}\right.$-THC). One of the three types that is now commonly cultivated is the fiber 
Table 1. Soil analysis

\begin{tabular}{cc}
\hline Soil type (soil triangle) & Clay (59.77\% clay, 30.92\% silt, and 9.32\% sand) \\
\hline $\mathrm{pH}$ & 7.8 \\
\hline Olsen-P & $23.39 \mathrm{mg} \mathrm{kg}^{-1}$ \\
\hline Available potassium $(\mathrm{K})$ & $240 \mathrm{mg} \mathrm{kg}-1$ \\
\hline EC $(1: 1)$ & $847.5 \mu \mathrm{s} / \mathrm{cm}$ \\
\hline Organic matter & $1.45 \%$ \\
\hline
\end{tabular}

Table 2. Monthly means of maximum $\left(\mathrm{T}_{\max }\right)$, minimum $\left(\mathrm{T}_{\min }\right)$ and average $\left(\mathrm{T}_{\text {average }}\right)$ air temperatures $\left({ }^{\circ} \mathrm{C}\right)$ and total rainfall $(\mathrm{mm})$ in the experimental site for 2019

\begin{tabular}{ccccc}
\hline Month & $\mathrm{T}_{\min }\left({ }^{\circ} \mathrm{C}\right)$ & $\mathrm{T}_{\max }\left({ }^{\circ} \mathrm{C}\right)$ & $\mathrm{T}_{\text {average }}\left({ }^{\circ} \mathrm{C}\right)$ & Rainfall $(\mathrm{mm})$ \\
\hline May & 5.5 & 31.6 & 18.4 & 15.8 \\
\hline June & 10.5 & 36.9 & 24.8 & 27.2 \\
\hline July & 15.1 & 37.6 & 25.5 & 40.0 \\
\hline August & 13.7 & 37.3 & 25.7 & 35.8 \\
\hline
\end{tabular}

Table 3. List of origin and sexual type of tested cultivars

\begin{tabular}{clcc}
\hline Cultivar & Origin & Genotypic expression & Maturity group \\
\hline 'Futura 75' & France & Monoecious & Late $(<145$ days $)$ \\
\hline 'Fedora 23' & France & Monoecious & Early $(<125$ days $)$ \\
\hline
\end{tabular}

type which has a low $\Delta^{9}$-THC content $(<0.5 \%)$ as opposed to high CBD content $(>0.5 \%)$ and is cultivated as feedstock for biofuel production, bio-building aspects, food industry (oil and meal), paper, cloth and litter production (Kinghorn et al., 2017; Arkell et al., 2019).

Medical cannabis and industrial hemp production have taken place in Greece in recent years, and the Greek hemp industry has continued to grow since it started five years ago (Folina et al., 2019). Still, there is absence of information about the optimum guidelines for hemp cultivation in Greece (Papastylianou et al., 2017) although the area under cannabis has expanded. Therefore, there is a clear need to establish optimal local agronomic practices for industrial hemp cultivation in order to optimize yield and quality of fiber and oil of hemp. The available scientific data relating to the topping effect on $C$. sativa are limited. The purpose of the present study was to determine the response of two commercial European industrial hemp cultivars to topping treatment during the 2019 growing season.

\section{Materials and methods}

\section{Experimental site and weather conditions}

A field experiment was carried out in Farsala area (Central Greece: latitude $39^{\circ} 18^{\prime} \mathrm{N}$, longitude $22^{\circ} 22^{\prime} \mathrm{E}$, altitude $160 \mathrm{~m}$ above sea level) during 2019 growing season. The soil type was a clay (Tab. 1). Weather data (rainfall, mean maximum and minimum air temperatures) were recorded daily and are reported as mean monthly data for the cultivation period (Tab. 2).

\section{Experimental design and treatments}

The experimental design was a split plot design, with three replications, two European hemp cultivars ('Fedora 23', 'Futura 75') characterized by different maturity group (Tab. 3 ) as the main plots and the topping treatments (untreated and topped) as sub-plots. Topping was done by cutting the main shoot of cannabis plants 
Table 4. The effect of cultivars and topping on height $(\mathrm{cm})$, leaf area $\left(\mathrm{cm}^{2}\right)$, plant fresh weight (g), plant dry weight (g), number of nodes on the main shoot, and number of inflorescences on secondary shoots of industrial hemp crop

\begin{tabular}{|c|c|c|c|c|c|c|c|}
\hline Cultivar & Topping & $\begin{array}{l}\text { Height } \\
(\mathrm{cm})\end{array}$ & $\begin{array}{l}\text { Leaf area } \\
\qquad\left(\mathrm{cm}^{2}\right)\end{array}$ & $\begin{array}{l}\text { Plant fresh } \\
\text { weight }(\mathrm{g})\end{array}$ & $\begin{array}{l}\text { Plant Dry } \\
\text { weight (g) }\end{array}$ & $\begin{array}{c}\text { No. of nodes } \\
\text { on the main } \\
\text { shoot }\end{array}$ & $\begin{array}{c}\text { No. of } \\
\text { inflorescences } \\
\text { on secondary } \\
\text { shoots }\end{array}$ \\
\hline \multirow{2}{*}{ 'Fedora 23' } & Topped & $210 a$ & $2612.75 b$ & 1302.13 & $390.63 a$ & $20.62 \mathrm{a}$ & $9.00 \mathrm{a}$ \\
\hline & Un-toppped & $253 a$ & $2325.25 d$ & 1097.87a & $329.36 a$ & $27.37 a$ & $5.00 \mathrm{a}$ \\
\hline \multirow{2}{*}{ 'Futura 75' } & Topped & $246 a$ & $2905.50 a$ & $1719.50 \mathrm{a}$ & $515.85 a$ & $24.25 a$ & $9.75 a$ \\
\hline & Un-topped & $286 a$ & $2433.87 \mathrm{c}$ & $1497.62 \mathrm{a}$ & $449.28 \mathrm{a}$ & $31.62 \mathrm{a}$ & $4.62 \mathrm{a}$ \\
\hline $\mathrm{F}_{\text {cultivar }}$ & & $* * *$ & $* * *$ & $* * *$ & $* * *$ & $* * *$ & ns \\
\hline $\mathrm{F}_{\text {topping }}$ & & $* * *$ & $* * *$ & $* * *$ & $* * *$ & $* * *$ & $* * *$ \\
\hline $\mathrm{F}_{\text {cultivars } \mathrm{x} \text { topping }}$ & & ns & $* * *$ & ns & ns & ns & ns \\
\hline
\end{tabular}

Note: F-test ratios are from ANOVA. Significant at *, ** and *** indicate significance at $\mathrm{p} \leq 0.05,0.01$ and 0.001 , respectively and ns: not significant. Values belonging to the same characteristic with different letters within a column denote significant differences between the interaction of cultivar and pruning treatments (LSD test, $\mathrm{p}<0.05$ ).

at $40 \mathrm{~cm}$ from the top of plants at 40 days after sowing. The plot size of each topping treatment was $10 \mathrm{~m} \times 10 \mathrm{~m}$ and consisted of 17 rows $60 \mathrm{~cm}$ apart. The soil was prepared by ploughing at a depth of about $25 \mathrm{~cm}$. Chemical fertilizer $(20-24-$ 0 ) was applied as a basal fertilizer at a rate of 250 $\mathrm{kg} \mathrm{ha}^{-1}$. Cannabis was sown on $11^{\text {th }}$ May 2019 at a rate of $20 \mathrm{~kg} \mathrm{ha}^{-1}$ using a standard grain drill, with an average sowing depth of $3 \mathrm{~cm}$. A drip irrigation system was installed in the experimental plots, watering every 25 days and the crop was kept free of weeds by hand hoeing.

\section{Plant measurements}

At harvest time (14 ${ }^{\text {th }}$ August 2019) when hemp inflorescence trichomes changed from white to milky white, samples from 10 plants were randomly selected from the middle rows of the plots and agronomical traits such as plant height, leaf area $\left(\mathrm{cm}^{2}\right)$, plant fresh weight (g), plant dry weight (g), number of nodes (on the main shoot), and number of inflorescences on secondary shoots were recorded. Plant samples were cut above soil level and plant height and fresh biomass were determined. Five of the harvested plant samples were oven-dried at $60^{\circ} \mathrm{C}$ for 48 hours in order to determine the total dry matter of the aboveground biomass. The remaining samples were used for the determination of CBD content and dry matter of inflorescences. Specifically, fresh inflorescences were subjected to the measurement of the CBD content in cannabis flowers using the GemmaCert device machine (GemmaCert Ltd., Israel) and then the fresh inflorescences were oven-dried at $60{ }^{\circ} \mathrm{C}$ for 48 hours and weighted to determine the inflorescence dry matter. Moreover, the compactness index $(\mathrm{g} / \mathrm{cm})$ was calculated for the inflorescences, according to the following formula: Inflorescence compactness index $=$

$=$ inflorescence dry matter $(\mathrm{g}) /$ bud lenght $(\mathrm{cm})$

\section{Data analysis}

The experimental data were subjected to statistical analysis according to split-plot design. The statistical analysis was performed with SigmaPlot 12 software (Systat Software Inc., San Jose, CA). Differences between means were separated using Least Significant Difference (LSD) test. All comparisons were made at the $5 \%$ level of significance.

\section{Results and discussions}

The analysis of variance of the experimental data revealed that plant height was significantly affected by topping and cultivars (Tab. 4). The plant height was higher in un-topped plants, the 


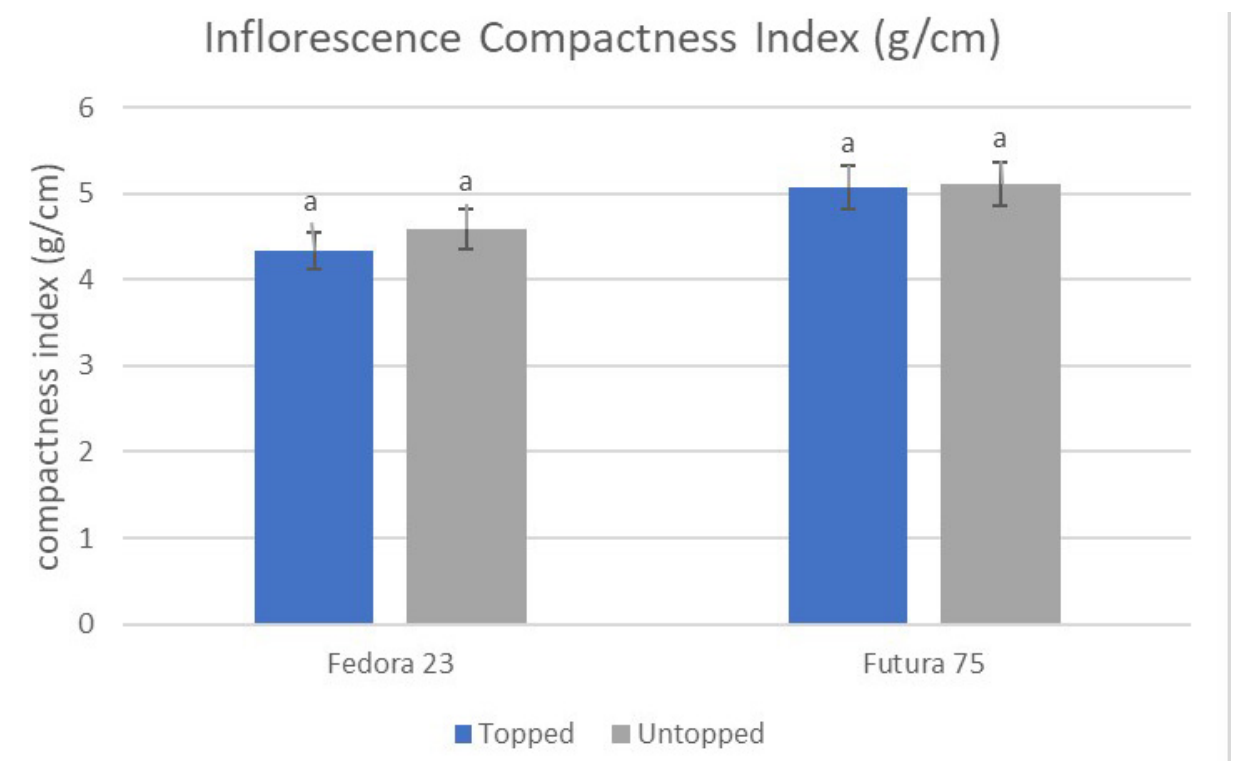

Figure 1. Inflorescence compactness index (g/cm) of two cultivars ('Fedora 23', 'Futura 75')

Vertical bars indicate the standard errors of the means. Different letters denote significant differences between the pruning treatments according to LSD test $(\mathrm{P}<0.05)$.

average value being $18 \%$ higher in comparison to topped plants. Decreases in plant height as a result of topping were reported by Obasi and Msaakpa (2005) in cotton and Aslam et al. (2008) in chickpea. In response to the effect of the cultivar factor in plant height, the mean values in 'Futura $75^{\prime}$ cultivar $(246 \mathrm{~cm}$ and $286 \mathrm{~cm}$ in topped and un-topped plants, respectively) were higher than in 'Fedora 23' cultivar $(210 \mathrm{~cm}$ and $253 \mathrm{~cm}$ in topped and un-topped plants). These results are in concordance with those of Papastylianou et al. (2017) demonstrating that 'Futura $75^{\prime}$ had the higher height in comparison to 'Fedora 23' cultivar.

The leaf area was significantly affected by the interaction of cultivar and topping. The leaf area was increased after topping $\left(2612.75 \mathrm{~cm}^{2}\right.$ in 'Fedora 23' and $2905.50 \mathrm{~cm}^{2}$ in 'Futura 75' cultivar, respectively) instead of un-topped plants (2325.25 $\mathrm{cm}^{2}$ in 'Fedora 23' and $2433.87 \mathrm{~cm}^{2}$ in 'Futura 75' cultivar) (Table 4). The fresh and dry weight was higher in topped plants probably due to the higher leaf area. The fresh and dry weights were affected by cultivar and topping, and the highest fresh and dry weights were obtained in topped 'Futura 75' plants (1719.50 g and $515.85 \mathrm{~g}$, respectively). Topping practices exerted significant variations in dry matter accumulation by the plants, and similar results indicating the positive effects of topping on dry matter have been reported by Kathiresan and
Duraisamy (2001) in dhaincha (Sesbania aculeata (Willd.) Pers.) and Marie et al. (2007) in okra (Abelmoschus esculentus (L.) Moench).

The number of nodes on the main shoot was higher on topped plants and affected by cultivar and topping. The number of nodes on the main shoot increased with 6.75 and 7.37 in 'Fedora 23', and 'Futura 75 ' topped plants, respectively, as compared with un-topped ones (Tab. 4). The number of inflorescences on secondary shoots was only affected by the topping treatment, and the highest values (9.00 and 9.75 in 'Fedora 23' and 'Futura 75', respectively) were recorded in topped plants. Increased yield attributes under the influence of topping may be attributed to improved growth characteristics, such as dry matter accumulation per plant coupled with extensive branching.

The inflorescence compactness index was only affected by the cultivars, and the highest values were observed in 'Futura 75 ' plants. The inflorescence compactness index of topped and un-topped 'Fedora 23' was 4.334 and $4.595 \mathrm{~g} /$ $\mathrm{cm}$, respectively, while the values for the topped and un-topped 'Futura 75' plants were 5.077 and $5.107 \mathrm{~g} / \mathrm{cm}$, respectively (Fig. 1).

The dry matter of total inflorescences was affected by the cultivars and topping. Concerning the cultivar factor effect, the mean value was the 


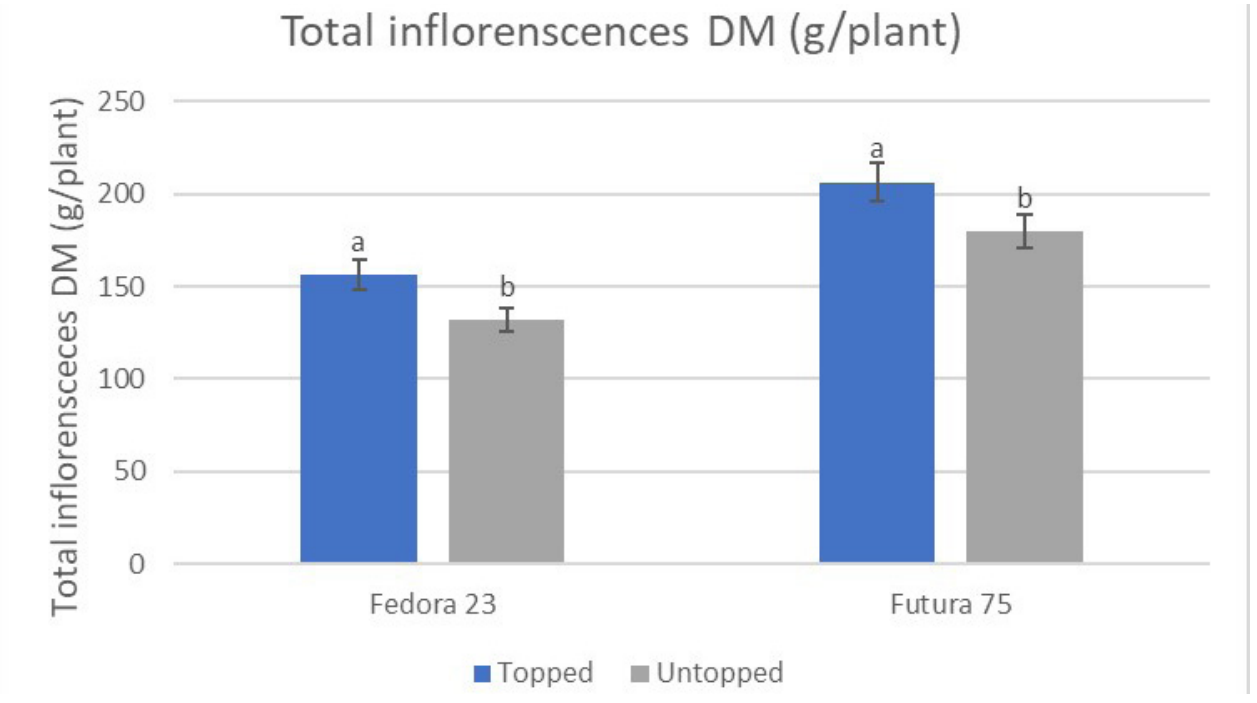

Figure 2. Total inflorescences dry matter (g/plant) of two cultivars ('Fedora 23', 'Futura 75') Vertical bars indicate the standard errors of the means. Different letters denote significant differences between the pruning treatments according to Least Significant Difference (LSD) test $(\mathrm{P}<0.05)$.

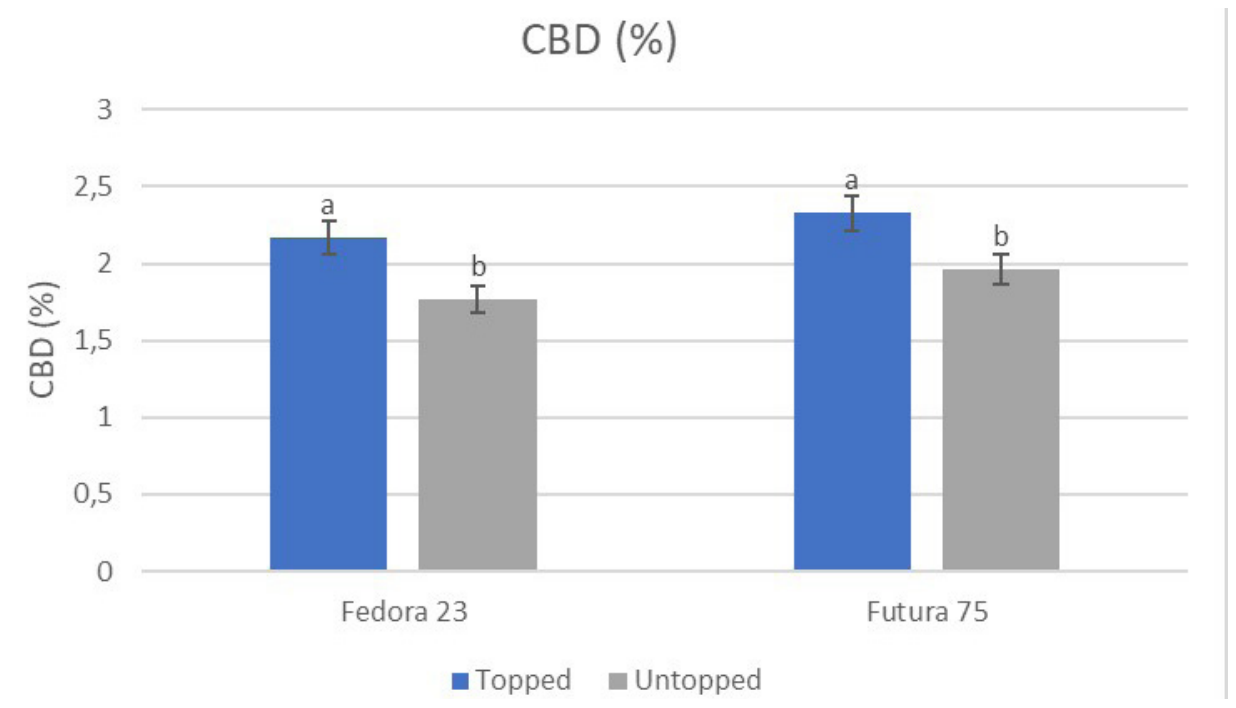

Figure 3. CBD content (\%) of two cultivars ('Fedora 23', 'Futura 75')

Vertical bars indicate the standard errors of the means. Different letters denote significant differences between the pruning treatments according to LSD test $(\mathrm{P}<0.05)$.

highest in 'Futura 75' (193 g/plant) followed by 'Fedora 23' (144 g/plant). The significant effect of genotype has been widely noticed. In the same line, Tang et al. (2016) noticed that inflorescence yield was 3.1 and $2.7 \mathrm{mg} \mathrm{ha}^{-1}$ in 'Futura 75 ' and 'Fedora 17 ' cultivar, respectively. In the topped plants, the values of total DM yield were substantially higher (206.3 g/plant in 'Futura 75' and $156.3 \mathrm{~g} / \mathrm{plant}$ in 'Fedora 23') than in the un-topped plants (179.7 and $131.8 \mathrm{~g} /$ plant in 'Futura 75' and 'Fedora 23', respectively) (Fig. 2). The higher dry matter yield under the effect of topping might be attributed to better growth characteristics which resulted in considerable improvement in yield attributing characters as number of inflorescences in secondary shoots and dry matter of inflorescences, and finally reflected into total dry matter of 
inflorescences (Kathiresan and Duraisamy, 2001; Marie et al., 2007).

Finally, the CBD content (\%) was affected by topping and cultivar; however, there was no interaction between topping and cultivar. The CBD content (\%) was $2.2 \%$ and $1.7 \%$ in topped and untopped 'Fedora 23' plants. The content in topped 'Futura 75' plant was $2.32 \%$, and in un-topped 'Futura 75' was $1.9 \%$ (Figure 3). Understanding of the biochemical origins of cannabinoids and how they relate to other secondary metabolites may be useful to speculate how pruning (topping) stress increased CBD content in this study. For instance, cannabinoids are closely related to some terpenoids that protect plants under stress. Cannabinoids and terpenoids share a similar biochemical pathway (Fellermeier et al., 2001; Hanuš et al., 2016). Several stressors, including environmental stressors and pruning, that normally up-regulate terpenoid synthesis and accumulation may do the same for some cannabinoids because of their related biochemical origins.

\section{Conclusion}

Hemp had a significant response to applied topping for both of the two studied cultivars. As it was expected, the number of inflorescences was higher in topped plants because of the high number of secondary shoots. The CBD content (\%) was higher in topped plants as pruning (topping) stress increased CBD content. In addition, CBD content (\%) was significantly influenced by the cultivar, and the highest values were found in 'Futura 75'. More research is needed to evaluate the effects of topping timing on cannabis inflorescence dry weight and secondary metabolism.

Acknowledgment: This work was funded by CBD Extraction PEF company. The code number of this project on the Special Account of the Agricultural University of Athens is 35.0021.

\section{References}

1. Allegret S, Bouloc P, Arnaud L (2013). The history of hemp. In: Bouloc P, Allegret S, Arnaud L (eds), Hemp: Industrial Production and Uses. CABI, Wallingford, pp. 4-26.

2. Amaducci S, Colauzzi M, Bellocchi G, Cosentino SL, Pahkala K, Stomph TJ, Westerhuis W, Zatta A, Venturi G (2012). Evaluation of a phenological model for strategic decisions for hemp (Cannabis sativa L.) biomass production across European sites. Industrial Crops and Products, 37: 100-110.

3. Arkell T, Kevin R, Stuart J, Lintzeris N, Haber P, Ramaekers J, McGregor I (2019). Detection of $\Delta^{9}$-THC in oral fluid following vaporized cannabis with varied cannabidiol (CBD) content: An evaluation of two point-of-collection testing devices. Drug Testing and Analysis, doi: 10.1002/dta.2687.

4. Aslam M, Ahmad HK, Himayatullah, Ayaz M, Ahmad E, Arshad M (2008). Effect of available soil moisture depletion levels and topping treatments on crop growth rate and total dry biomass in chickpea. Journal of Agricultural Research, 46(3): 229-243.

5. Farooq A, Sajid L, Muhammad A (2006). Analytical characterization of hemp (Cannabis sativa) seed oil from different agro-ecological zones of Pakistan. Journal of the American Oil Chemists' Society, 83(4): 323-329.

6. Fellermeier $\mathrm{M}$, Eisenreich $\mathrm{W}$, Bacher A, Zenk $\mathrm{MH}$ (2001). Biosynthesis of cannabinoids: In-corporation experiments with 13C-labeled glucoses. European Journal of Biochemistry, 268: 1596-1604.

7. Folina A, Roussis I, Kouneli V, Kakabouki I, Karidogianni S, Bilalis D (2019). Opportunities for cultivation of medical cannabis (Cannabis sativa L.) in Greece. Scientific Papers. Series A. Agronomy, 62(1): 293-300.

8. Hanuš LO, Meyer SM, Muñoz E, Taglialatela-Scafati O, Appendino G (2016). Phytocannabinoids: A unified critical inventory. Natural Product Reports, 33: 13571392.

9. Jonaitienè V, Jankauskienė Z, Stuogè I (2016). Hemp Cultivation Opportunities and Perspectives in Lithuania. In: Fangueiro R, Rana S (eds), Natural Fibres: Advances in Science and Technology Towards Industrial Applications. RILEM Bookseries, vol 12. Springer, Dordrecht.

10. Kathiresan G, Duraisamy K (2001). Effect of clipping and diammonium phosphate spray on growth and seed yield of dhaincha (Sesbania aculeata). Indian Journal of Agronomy 46(3): 568-572.

11. Kinghorn AD, Falk H, Gibbons S, Kobayashi (2017). Phytocannabinoids: Unraveling the Complex Chemistry and Pharmacology of Cannabis sativa. Progress in the Chemistry of Organic Natural Products, 103. Switzerland: Springer.

12. Marie AI, Ihsan A, Salih SH (2007). Effect of sowing date, topping and some growth regulators on growth, pod and seed yield of okra (Abelmoschus esculentus L.M.). In: African Crop Science Conference Proceedings. 8: 473-478.

13. Obasi MO, Msaakpa TS (2005). Influence of topping, side branch pruning and hill spacing on growth and development of cotton (Gossypium barbadense L.) 
in the Southern Guinea Savanna location of Nigeria. Journal of Agriculture and Rural Development in the Tropics and Subtropics, 106(2): 155-165.

14. Papastylianou P, Kakabouki I, Travlos I (2017). Effect of Nitrogen Fertilization on Growth and Yield of Industrial Hemp (Cannabis sativa L.). Notulae Botanicae Horti Agrobotanici Cluj-Napoca, 46(1): 197-201.
15. Tang $K$, Struik $P$, Yin $X$, Thouminot C, Bjelková $M$, Stramkale V, Amaducci S (2016). Comparing hemp (Cannabis sativa L.) cultivars for dual-purpose production under contrasting environments. Industrial Crops and Products, 87: 33-44.

16. Turner CE, Elsohly MA, Boeren EG (1980). Constituents of Cannabis sativa L. XVII. A Review of the Natural Constituents. Journal of Natural Products, 43(2): 169243. 